\title{
SOBRE LA INTERPRETACIÓN SIMBÓLICA Y TRADUCCIÓN DE J. L. BORGES EN RADIVOJE KONSTANTINOVIĆ
}

\author{
UDC 821.134.2(82).09 Borges J. L. \\ $81^{\prime} 255.2$
}

\begin{abstract}
Aneta Trivić
Universidad de Kragujevac, Facultad de Filología y Artes, Departamento de Estudios Hispánicos, Kragujevac, Serbia
\end{abstract}

\begin{abstract}
Resumen. Este trabajo presenta doble finalidad: por un lado representamos los temas, símbolos y metáforas empleadas por J. L. Borges en su obra prosaica y y ponemos especial atención en su recepción e interpretación en el ámbito serbio (en primer lugar nos centramos en el laberinto como símbolo de la construcción espacio-temporal, psicológica, existencial u onírica). Paralelamente exploramos las críticas y observaciones que sobre Borges ha elaborado el profesor Radivoje Konstantinović, uno de los mejores conocedores de la obra borgeana. El segundo objetivo que perseguimos concierne el análisis traductológico: examinamos las soluciones y métodos traductológicos empleados en textos serbios por Konstantinović. En tal análisis partimos de la estructuración sistemática y jerárquica del sistema lingüístico y comentamos las soluciones gramáticas y estilísticas interesantes para los serbiohablantes. El corpus principal está basado en el relato La casa de Asterión y su traducción serbia Asterionov dom (ZUNS). En la investigación nos apoyamos en los métodos de interpretación simbólica / metafórica (cuando representamos y analizamos ideas y símbolos dominantes en la obra prosaica de J.L.Borges), análisis lingüístico y traductológico del texto en prosa y análisis contrastivo (cuando utilizamos los corpus paralelos para comparar las distintas soluciones traductológicas del mismo texto).
\end{abstract}

Palabras clave: traducción, símbolo, metáfora, laberinto, J. L. Borges, R. Konstantinović.

Submitted July 2, 2019; Accepted September 23, 2019

Corresponding author: Aneta Trivić

University of Kragujevac, Faculty of Philology and Arts

E-mail: anetatrivic@gmail.com 
De todos los escritores que he traducido, Borges era el que más me enriqueció.

(Konstantinović 1997: 226)

\section{EL SIMBOLISMO Y METÁFORA EN J. L. BORGES}

Jorge Luis Borges, el gran narrador, poeta, traductor, crítico y filósofo «no sólo fue uno de los mayores escritores del siglo XX; fue asimismo uno de los que mejor lo representaran» (Konstantinović 1997, 28). Este 'ciudadano del mundo' era como una encarnación de la fusión de temas personales y generales, locales y universales, de la patética e ironía o de la erudición e indiferencia (Konstantinović 1997, 30). Los motivos literarios predominantes en Borges eran: el laberinto, los espejos, el infinito, los sueños, el tiempo. El autor investigaba las relaciones del caos y del orden, las ideas del destino, la identidad, la historia de un hombre, el carácter ilusorio de la realidad, la ley de la causalidad, el anverso y el reverso de una misma realidad, el recuerdo y el olvido (Carmen Balart y Césped Benítez 2010).

Cuando se trata de la recepción e interpretación de la obra de Borges en Serbia, cabe notar que cronológicamente «los lectores serbios acogieron a Borges como escritor suyo, primero en tanto que narrador, partiendo de las Ficciones, publicadas en Belgrado en 1963, luego como poeta y finalmente como crítico» (Matić y Nedić 1997, 9). A partir de entonces hasta hoy en día estaban apareciendo las traducciones nuevas de sus obras y con orgullo podemos constatar que en mayor número de casos su opus prosaico tiene dos o más traducciones serbias (La espera, Deutsches Requiem, El jardín de los senderos que se bifurcan) y el Alef cuenta con hasta cuatro distintas traducciones al serbio. Igualmente importante es el hecho de que los traductores e investigadores borgeanos son los traductores renombrados y premiados (en primer lugar Radivoje Konstantinović y Radoje Tatić, luego Krinka Vidaković, Ljiljana Popović-Anđić, Dragana Bajić etc.). En 1996 en Belgrado tuvo lugar un Simposio Internacional dedicado a Borges, con motivo del décimo aniversario de su muerte (que contaba con la presencia de su viuda, María Kodama). Entre otros asuntos, se examinaron las influencias de la literatura de Borges en los escritores serbios contemporáneos. ${ }^{1}$

El profesor Konstantinović, como gran crítico y traductor de la obra borgeana que ha traducido su poesía y prosas cortas, destaca que los libros de Borges siguen reeditándose y atrayendo mucha atención. A la vez pone de relieve que la obra de Borges es muy amena para leer, aunque no siempre fácil de entender (Konstantinović 1997, 27). Como mayor mérito literario de Borges subraya su capacidad de:

\footnotetext{
${ }^{1}$ En primer lugar Borges se ha relacionado con Kiš; diversos son los elementos comunes, tales como la metáfora de los espejos o la ironía. El mismo Kiš observó que «la historia universal de la infamia es precisamente de lo que se habla en la Sepultura Boris Davidovič» (Šukalo 1997, 140).

«El sentimiento de herencia literaria es lo que tanto Kiš como Borges, cada uno en su ambiente civilizacional, culturológico e incluso ideológico, conciben e identifican de distintas maneras, pero que al mismo tiempo indica la proximidad de sus posturas con respecto a la literatura y al arte. No sin justificación la bibioteca de Babel borgesiana termina en La enciclopedia de los muertos, de D. Kiš, ya que corresponden entre sí como un palimpsesto típico» (Šukalo 1997, 140).

En cuanto a otros autores serbios, Delić destacó que «Milorad Pavić es particularmente próximo a Borges en cuanto a su modo de ver al lector, así como en cuanto a la relativización del autor» y que «Milisav Savić es un gran admirador del procedimiento reduccionista de Borges tanto en las narraciones como en los ensayos» (Delić 1997, 290).
} 
«subir lo nacional, lo específico de una comunidad de habla a un nivel general, universal. Precisamente por haber tratado la historia y tradición argentina como cualquier otra, por ejemplo la escandinava o antigua griega, Borges logró que el lector extranjero aceptara lo nacional y lo argentino como una forma universal de la expriencia humana» (Konstantinović 1997: 27; traducción A.T.)

Entre los temas recurrentes, uno de las más frecuentes es el laberinto; laberinto como «construcción física, espacio-temporal, visual, nemotécnica, psicológica, onírica, religiosa, existencial, metafísica» (Carmen Balart y Césped Benítez 2010, 2). «El laberinto, como tema obsesivo de Borges, significa al mismo tiempo, lo ininteligible del mundo y su duración» (Pejčić 1997, 171).

¿Por qué destaca el profesor Konstantinović $(1997,27)$ que Borges es muy agradable de leer pero difícil de entender? Seguramente por su erudición, conocimiento enciclopédico de distintas civilizaciones y costumbres, connotaciones evasivas y ambiguas y, al final, por su lenguaje simbólico y metafórico. Los temas en la obra de Borges no representan ninguna novedad en el mundo literario; son los temas eternos (Konstantinović 1999, 18) que tratan la relación entre el hombre y el mundo externo, la muerte, la transitoriedad, el sentido de la vida, la felicidad, la identidad humana etc. Pero los mensajes que Borges nos manda a través de sus símbolos y alusiones sutiles muchas veces dificultan la interpretación del mensaje (por ejemplo las metáforas y metonimias que se basan en las relaciones de similitud y proximidad, o en la discrepancia y distancia, las alusiones que evocan distintos arquetipos y tendencias filosóficas). ${ }^{2}$

«Las características principales de las metáforas borgeanas son la posibilidad de reducirlas en un grupo de arquetipos y una funcionalidad estricta. (...) Su metáfora evoca abundancia de asociaciones - profundamente íntimas, históricas, literarias, filosóficas. Ella es reconocible, pero al mismo tiempo es original, porque es reconstruida y fortalecida con nuevos y espontáneos compuestos de palabras» (Konstantinović 1999, 18; traducción A.T.)

No existe la interpretación de una obra de Borges que no incluyera el dominio metafórico y simbólico. «Si existe una figura retórica sobre la que Borges reflexiona profundamente es la metáfora, una de las más poderosas figuras semánticas (...)» (Palomo García 2010, 32). La potencia de la metáfora yace en sus posibilidades divulgadoras que, prácticamente, son ilimitadas (Palomo García 2010, 32). «Quizá la Historia Universal sea la historia de unas cuántas metáforas» diría el mismo Borges (apud Puslojić 1997, 79) y también diría que para él «hablar era metaforizar» (García Ramos 2002, 121).

\footnotetext{
${ }^{2}$ Entendemos la metáfora como un fenómeno de doble sentido: por un lado como la máxima representante de la figura del tropo, que junto con alegoría, metonimia, símbolo etc. consiste en uso de palabras en su sentido figurado (opaco, no literal) para describir algunos conceptos (Rečnik književnih termina, traducción A.T.). Similarmente, entendemos el símbolo como el recurso que se usa para dar nuevo significado a un objeto concreto, para darle un significado simbólico. En otras palabras, un lexema designa un objeto concreto, cuando realmente se refiere a uno (o más) fenómenos abstractos (Rečnik književnih termina, traducción A.T).

Por otro lado, la metáfora (en sentido de la metáfora conceptual y como el término de la lingüística cognitiva) no se entiende como un ornamento estilístico ni una simple figura retórica, sino más bien como un fenómeno de cognición humana. Igual que lenguaje en general, la metáfora se concibe como la parte integrada de todas las capacidades cognitivas humanas (Lakoff y Johnson 1980, Kevecses 2010, Talmy 2000, Langacker 1987, Johnson 1990, etc.). Para los cognitivistas, la metáfora sirve para entender y experimentar un tipo de fenómenos en términos del otro (...) y de ahí facilita la conceptualización y estructuración del significado (Iñesta Mena \& Pamies Bertrán 2002, 65). Podemos observar que en Borges estas dos funciones metafóricas se entrelazan.
} 
«Para los conocedores (para los intérpretes y para los lectores) del irresistible y misterioso PALACIO BORGESIANO de poesía, prosa y ensayos suyos, que se erige por todas partes, abierto eternamente cual el brillante Cristal o el oscuro Laberinto, no resulta extraño la mención de estas nociones que constituyen el material básico de sus metáforas globales: el sueño, el espejo, el libro, la clave, la biblioteca, el desierto, el castillo, el tigre, el ruiseñor, la serpiente, el espejismo, la máscara, el doble, el laberinto, el testigo, el suicida, el duelo, el pasado, el cosmos, el hacedor, la letra de Dios, la cifra, la clepsidra, el río del tiempo...y así sucesivamente.» (Puslojić 1997, 82, 83)

La presencia de distintos símbolos, metáforas, alusiones y otras figuras en la poesía y prosa borgeana, provoca el incremento de mensajes connotativos, encubiertos en sus textos. Como si no existiera el párrafo o la oración que no esconda algún sentido o símbolo, símbolo escondido en una especie narrativa que resulta ser por lo menos insólita, si no enigmática, símbolo disimulado en el laberinto lingüístico que rompe la lógica del enunciado y rompe la relación tiempo-espacio a la que estamos acostumbrados. Como si sus sintagmas y oraciones siempre aludieran a los fenómenos distintos de los que aparecen en el texto, a los fenómenos más abstractos de lo que pareciera. Tal vez fueron estas las razones por las que nuestro ilustre escritor Danilo Kiš, después de haber leído la primera traducción de Ficciones al serbio, dividió el curso de la literatura en dos épocas: la de antes y la de después de Borges. Los motivos y símbolos borgeanos están interpretados por otro traductor ilustre, Branislav Prelević en las palabras siguientes:

«La conciencia subjetiva en Borges está relacionada con la conciencia colectiva. La conciencia del hombre, en forma de espejos, y la realidad objetiva, en forma del Universo, están confrontados uno al otro formando la eternidad. El laberinto de Borges está compuesto por los círculos concéntricos. La circularidad es sinónimo del tiempo infinito. Aunque este tiempo circular o laberíntico, tiene el significado de la perfección, su antónimo está encarnado en el caos total, que también figura en la obra de Borges». (Prelević 1997, 105; traducción A.T.)

Solía decir Borges para sí mismo «Soy un hombre del siglo XIX extraviado en éste». Es precisamente en esta encrucijada témporo-locutiva donde intentamos ejemplificar el simbolismo de lo idiosincrásico y de lo universal en la prosa de Borges. Creemos que el laberinto es uno de los ejemplos más ilustrativos de cómo Borges entendía el tiempo y espacio. En la interpretación de Danilo Kiš:

«El laberinto y los espejos de Borges, los dos mitos más extendidos en su obra, son en realidad la metáfora literaria, la metáfora de la literatura borgeana: en su literatura el hombre se pierde en el laberinto: una fuente nos lleva hasta un pasillo falso, que realmente no tiene salida, luego el pasillo falso nos lleva por caminos laterales a una sala falsa, etc. Nadie puede llegar a Minotauro - el dueño del mundo subterráneo literario - ni dejarlo, sin estar castigado. Minotauro existe para guardar la creación y apartarla de los necios y de los malentendidos. Igualmente metafóricos son los espejos borgeanos: los mundos se están mirando uno al otro, igual que los libros, y ese miseen-abîme, esos abismos que surgen de otros abismos de sentido y desde los que se hunde más profundamente, a otros abismos vastos; estas son meras variaciones a los temas de escritura y lectura - esa eterna mirada en el espejo dentro del más grande de todos los laberintos: la biblioteca, la tumba de todas las ilusiones». (Kiš 1997, 339; traducción A.T.) 
El espejo y laberinto sirven en Borges como símbolos de debilidad: en el espejo (que representa el mundo de reproducción) el hombre se mira y reconoce propias debilidades ante el enigma final de la vida (Lukić 1997, 212). «Esta debilidad va a culminar en el tema del laberinto; el laberinto en Borges simboliza la vaguedad del mundo y se manifiesta en distintas formas: la ciudad, el río, la piel del tigre, la biblioteca» etc. (Lukić 1997, 212). Para Borges la búsqueda de la salida del laberinto en realidad está dirigida hacia la búsqueda del escritor, de sus aficiones, ficciones, sueños.

«Si el mundo es un laberinto, también lo es el escritor. Y Borges intentaba ser uno (escritor / laberinto), por eso es difícil descifrar su opus y la llave para descifrarlo es misteriosa y se escapa al lector; igual de difícil es el proceso de descifrar a Borges como personalidad. Sin embargo, Borges nos invita siempre a emprender esta aventura investigativa y misteriosa, independientemente de su resultado final» (Lukić 1997, 213; traducción A.T.).

\section{2. BORGES Y TRADUCCIÓN}

Borges ante todo era creador. Procuraba crear mundos y personajes nuevos, mezclarlos con los personajes históricos y situarlos en nuevos contextos.

«(...) Toda su vida se dedicó, desde su obra creativa, desde su obra crítica, desde sus comparecencias públicas, académicas o extraacadémicas, a demostrarnos que no hay diferencia entre lenguaje literal y lenguaje figurativo; ambos son vanos intentos de apalabrar una realidad siempre inasible. Su postura se instala en una tradición crítica que se inicia en Cicerón y llega a nuestros días» (García Ramos 2002, 121).

Cuando se trata de su producción literaria, cabe mencionar que la traducción, junto con la creación literaria, ocupaba un lugar importantísimo en su vida. Franz Kafka, Bernard Shaw, Walt Whitman, Edgar Allan Poe, Virginia Woolf, Rudyard Kipling, Hermann Hesse, entre otros, figuran en el repertorio traductológico de Borges. Este gran poeta, ensayista y narrador traducía mucho, y al mismo tiempo exponía sus ideas sobre la traducción. Según Kristal: «la traducción es quizás el tema más recurrente en los ensayos de Borges. Sus traducciones son documentos iluminadores para comprender la gestación de sus ficciones. La mayoría de ellas exploran de manera explícita el tema de la traducción» (Kristal 1999, 3).

Para Borges, la traducción no es solamente un proceso repetitivo o interpretativo, más bien es un proceso creativo. En sus palabras «el original es infiel a la traducción» (Borges 1981, apud Kristal 1999, 3) se puede resumir su doctrina traductológica. Kristal destaca que para el autor argentino «una traducción puede ser mejor que un original. Si el original contiene detalles y aspectos confusos y oscuros puede ser infiel a la idea de la obra» (Kristal 1999, 4). Además, para Borges «la traducción no es un traslado de un idioma a otro, sino una modificación de un texto que conserva ciertos aspectos y elimina otros» (Kristal 1999, 3).

En cuanto a la competencia traductora, el autor la apreciaba como la habilidad superior, la habilidad que requería el don de creación literaria.

«Suele presuponerse que cualquier texto original es incorregible de puro bueno, y que los traductores son unos chapuceros irreparables, padres del frangollo y de la mentira. Se les infiere la sentencia italiana de traduttore traditore y ese chiste basta para condenarlos» (Borges 1997, 256). 
Cuando analizaba los procedimientos y procesos traductológicos, Borges destacaba dos modos principales de traducción: la traducción literal, «que conserva los detalles» y la traducción más libre, denominada la perífrasis por parte del autor, que «conserva el significado. La traducción que conserva el significado del original puede ser más fiel que la traducción que conserva los detalles» (Kristal 1999, 3). «Universalmente, supongo que hay dos clases de traducciones. Una practica la literalidad, la otra la perífrasis. La primera corresponde a las mentalidades románticas; la segunda a las clásicas» (Borges 1997, 257).

Obviamente Borges inclinaba hacia la segunda 'clase de traducción'. Para él la traducción no era mera transferencia del texto de una lengua a otra, sino la transformación del texto que tenía como finalidad la mejora de la expresión. La mejora de la expresión en texto meta se consigue mediante la simplificación del enunciado, eliminación de elementos redundantes o inconsistentes o mediante enriquecimiento del texto original añadiendo distintos matices.

Borges no era formalista, y para él la prosa y la poesía eran las dos caras de misma moneda, dos modos de expresar los mismos sentimientos y símbolos; él no hacía la distinción formal entre el género lirico y narrativo. Para Konstantinović (1999, 25) Borges el poeta y Borges el narrador se presentaban mejor en sus poemas en prosa, cortas formas que él mismo denominaba parábolas.

Por nuestra parte, y siguiendo las ideas de Borges sobre la importancia de la labor traductológicá, acogemos la premisa de Newmark $(2010,42)$ dirigida precisamente a los traductores:

«Ustedes trabajan continuamente en dos niveles, el real y el lingüístico, el da la vida y el lenguaje, el de la referencia y el sentido, pero escriben, componen, en el nivel lingüístico, y su labor consiste en lograr referencial y pragmáticamente la mayor correspondencia posible con las palabras y oraciones del texto original. Por tentador que sea permanecer en ese nivel —más simple, y por lo general simplificado- de la realidad (el mensaje y su función) del profano en la materia, tienen que obligarse a volver, en tanto en cuanto el lector pueda soportarlo, a las peculiaridades del sentido de la lengua original».

\section{SOBRE LA TRADUCCIÓN Y TRADUCTOLOGÍA}

Otro tema de nuestro interés son diferentes aspectos traductológicos en los procesos de transmisión e incorporación de los textos borgeanos al serbio. Parece que hoy en día los estudios traductológicos siguen siendo muy actuales y que las investigaciones comparativas y contrastivas (de las culturas, tradiciones, mercados, literaturas y lenguas distintas) se están promoviendo cada vez más. El trabajo de los traductores e intérpretes es altamente valorado, incluso en las circunstancias ambivalentes que nos rodean: por un lado atestiguamos el desarrollo de los procesos globalizadores e inter/transnacionales en los que se eliminan las fronteras y por otro lado observamos los procesos migratorios en los que surgen nuevas fronteras.

Consideramos muy importante el trabajo de los traductores, no solamente en los servicios y actividades con fines prácticos y específicos, sino también en el campo literario, cultural, educativo, etc. Las traducciones también desempeñan una función fundamental en el ámbito lingüístico (teórico y aplicado) suministrando el material auténtico para los estudios contrastivos, para el trabajo didáctico e igualmente en el campo lexicográfico y en la elaboración de los corpus. 
En nuestra crítica traductológica inclinamos hacia la corriente tradicional entendida esta en términos de Nord $(1998,2002,2007)$ y en términos de la Escuela Traductológica de Leipzig de Kade (1965). Más específicamente, Nord (1998) basa su teoría de la traducción en las distintas interpretaciones del término unidad traductológica y distingue los siguientes enfoques y concepciones traductológicos: 1) enfoque estrictamente lingüístico, 2) enfoque pragmalingüístico o lingüístico-textual, 3) enfoque hermenéutico, 4) enfoque psicolingüístico orientado hacia el proceso de traducción, 5) enfoque semiótico y 6) enfoque funcionalista.

Tradicionalmente se ha cultivado como dominante el enfoque lingüístico, según el cual «las unidades de traducción pueden encontrarse en todos los niveles del habla» (Nord 1998, 67). Se refieren los niveles del habla a la estructuración jerárquica de los elementos lingüísticos: desde los más bajos (como son fonemas en el habla o grafemas en la escritura), a través de los morfemas, lexemas, modismos y colocaciones, hasta los niveles más altos como son las oraciones complejas y las unidades textuales. Otro enfoque que acogemos en nuestra investigación es el pragmático o pragmalingüístico. Este toma en consideración los principios de la lingüística textual, especialmente los factores situacionales que determinan la producción, recepción e interpretación del mensaje. Nord acepta las premisas de los traductólogos Poulsen, Reiss y Vermeer cuando afirma que la unidad traductológica primaria es el texto, «mientras que las palabras le interesan al traductor nada más que como 'elementos textuales' (Nord 1998, 67). ${ }^{3}$

Dentro de esta corriente tradicionalista el acto de traducir consiste en la «transformación del mensaje (pensamientos, sentimientos, deseo, orden) previamente expresado en una lengua a otro mensaje, que tiene el mismo valor pero está expresado en otra lengua» (Ivir 1978, 9; traducción A.T.). Esto directamente implica que el «destinatario / receptor del mensaje traducido debe recibir el mismo contenido como el receptor del mensaje en texto original» (Ivir 1978, 9; traducción A.T.). Tradicionalmente se ha hecho la distinción entre los términos traducción y traductología. Por una parte existe la habilidad, «un saber hacer que consiste en saber recorrer el proceso traductor, sabiendo resolver los problemas de traducción que se plantean en cada caso» (Hurtado Albir 2007, 28, 29), que es precisamente la traducción. Por otra parte, existe la disciplina que estudia la traducción; «se trata, pues, de un saber sobre la práctica traductora» (Hurtado Albir 2007, 25).

Para Hurtado Albir $(2007,28,29)$ cuatro son los requisitos básicos para el proceso traductológico: 1) la razón de la existencia de la traducción es la distinción que existe entre las lenguas y las culturas; 2) la traducción tiene el objetivo comunicativo; 3) el que necesita la traduccion es el receptor porque no conoce la legua y cultura del texto original 4) la traducción está condicionada por el objetivo que puede variar dependiendo de la situación comunicativa (Hurtado Albir 2007, 28 - 30 ).

Lo que Hurtado Albir destaca como otro factor relevante para el proceso traductológico, y en esto coincide completamente con Newmark (2006), es la importancia de la competencia traductológica del traductor (hoy se denomina también la competencia

\footnotetext{
${ }^{3}$ En cuanto a otros enfoques traductológicos, el hermenéutico afirma que «entre las unidades más grandes y las más pequeñas de un texto no existe una relación de absorción» y que «el efecto comunicativo de un texto se deriva (...) de la composición específica de sus componentes» (Nord 1998, 68). Como las unidades traductológicas se entienden las unidades de habla o de discurso y la traducción adecuada requiere las capacidades hermenéuticas del traductor. Luego, el enfoque psicolingüístico entiende que el traductor es la figura central en el proceso traductológico, y que la calidad de la traducción dependerá de sus capacidades lingüísticas y de su dominio de la lengua origen y lengua meta, pero también de sus capacidades cognitivas en general, de sus conocimientos extralingüísticos y afinidades personales. Finalmente, el enfoque funcionalista acentúa el texto completo como la unidad traductológica. (Nord 1998, 68, 69).
} 
mediadora). Esta competencia abarca habilidades lingüísticas y extralingüísticas del traductor (las extralingüísticas son, por ejemplo, reconocimiento de los elementos culturales del texto meta, inclusión de los elementos culturales del texto origen en texto meta, conocimientos sobre los temas tratados en el texto etc.). Newmark (2006, 18) también observó que el traductor debe poseer un sentimiento y sabor peculiares para disfrutar de su lengua, o un sexto sentido que no lleva nada místico, sino presupone una mezcla de la inteligencia, sensibilidad e intuición, aparte de conocimientos.

\section{ANÁlisis TRAdUCTOLÓGICO DE LA CASA DE ASTERIÓN}

En esta ocasión basamos el análisis traductológico en el cuento cuyo motivo central es el laberinto: La casa de Asterión. Comentaremos algunos puntos que consideramos interesantes para el análisis linguiístico, estilístico y traductológico especialmente desde el punto de vista de los serbiohablantes.

La voz del protagonista nos está llevando por el relato La casa de Asterión, y este tiene forma de monólogo. El título del cuento es una metáfora que

«alude a un espacio al que desde el comienzo podríamos pensar (...) como un lugar acogedor y tierno. Los hechos se encargarán de demostrarnos que tal circunstancia es falsa, porque esa casa es un laberinto y porque ese laberinto es la prisión del pobre Asterión, el lugar en donde habita aguardando la muerte y acompañado por la soledad» (Quintana Tejera 2011).

El relato comienza in medias res, ya han ocurrido las circunstancias explicadas por el narrador, se supone que el lector está familiarizado con el protagonista y su vida, que ya está introducido a él desde el principio ( $Y$ la reina dio a luz un hijo que se llamó Asterión). Sin embargo, hasta el final no se revela la identidad de este protagonista, de este príncipe: cuál es su carácter, su modo de ser. De esta manera Borges mantiene al lector en un estado de ignorancia, juega con él, llevándolo por el cuento como por un laberinto de inconciencia, curiosidad, ansiedad e incertidumbre. Los aspectos del laberinto que Borges explota en esta obra son «la antigüedad del tema en la cultura y (...) pensamiento griego; (...) y el simbolismo que asocia al laberinto con el infinito» (Quintana Tejera 2011). En el relato Borges obviamente ha construido dos laberintos: uno para el lector y otro para el protagonista.

El marco situacional del cuento (y el centro de la narración) es la casa del Asterión a la que el protagonista describe de este modo:

(1) No hallará pompas mujeriles aquí ni el bizarro aparato de los palacios pero sí la quietud y la soledad. Asimismo hallará una casa como no hay otra en la faz de la tierra. (Borges 2003, 77)

(1a) Taj ovde neće naći ženstvenu raskoš niti čudnu velelepnost palata već mir $i$ samoću. Naći će kuću kakve nema nigde na Zemljinom šaru. (Borhes 1999, 59)

Desde el punto de vista de la crítica traductológica es interesante comentar el uso del sintagma nominal Zemljin šar (las rayas de la Tierra) en la traducción serbia, porque se trata de una combinación de muy baja frecuencia de uso que, incluso, puede estar marcada como rara o arcaica. El sintagma en la faz de la tierra en español tampoco es común en el habla y refleja fielmente el estilo erudito que cultivaba Borges en sus obras. 
Aunque, según RMS šar es rusismo que coloca precisamente con el adjetivo zemaljski ('de la tierra') para denotar tierra, planeta, en el contexto borgeano no podemos ignorar otra connotación que evoca: las rayas del tigre (tigrove šare), que es otro símbolo muy explotado en Borges.

Estos matices semánticos (referidos a los significados denotativos y connotativos que son disponibles solamente al lector que conoce la obra de Borges) nos pueden facilitar la interpretación del significado y también los análisis traductológicos en un nivel contrastivo. $\mathrm{Si}$, por ejemplo, quisiéramos comparar esta traducción con otra traducción del mismo texto (Aleksandar Grujičić, Paidea 2004, 42), veríamos que la otra también utiliza sintagma zemaljski šar, lo que indica que se basa en la traducción previamente hecha en 1999 de ZUNS.

A continuación del cuento el protagonista explica que él no sale de su casa, pero asegura al lector / interlocutor que sus «puertas (cuyo número es infinito) están abiertas día y noche a los hombres y también a los animales».

(2) ¿Repetiré que no hay una puerta cerrada, añadiré que no hay una cerradura? (Borges 2003, 77)

(2a) Treba li da ponovim da nijedna vrata nisu zatvorena, da dodam da nema nijedne jedine brave? (Borhes 1999, 59)

Vemos que la construcción interrogativa del texto original usa el verbo en el futuro simple, tiempo que en español expresa la intención y el plano relacionado con la acción futura, pero al mismo tiempo expresa la probabilidad o posibilidad de la realización de una acción. La forma interrogativa añade el matiz dubitativo y el tono de irritación a la narración: el protagonistanarrador ya había destacado que él no era ningún prisionero y que podía salir de su 'casa' cuando quisiera ¿para qué debe repetirlo otra vez? La traducción serbia mantiene la forma interrogativa, pero el valor temporal se transforma en la oración declarativa de presente, y además contiene el verbo modal trebati, lo que implica la redundancia de la información introducida por el narrador (como si el narrador quisiera decir: aunque ya ha se lo he explicado o ¿ahora hace falta añadir más detalles?) El traductor igualmente hubiera podido optar por el verbo hteti: hoću li da ponovim.? o por una construcción descriptiva y perifrástica: Ima li potrebe da ponavljam...?. Todas estas posibilidades, igual que la traducción de Konstantinović, refuerzan la interrogación y añaden un tono de reproche al lector.

La traducción posterior de Paidea ofrece una solución más explicativa:

(2b) Zar treba da ponavljam da nijedna vrata nisu zatvorena, ili da dodajem kako nema nijednog jedinog zasuna? (Borhes 2004: 42).

Aquí se ve claramente cómo el aspecto verbal (ponavljam en vez de ponovim, dodajem en vez de dodam) influye al tono narrativo y crea el ambiente de la impaciencia y desasosiego.

Para Almeida $(1999,45)$ la casa, o mejor dicho, el laberinto de Asterión no es una estructura caótica donde uno simplemente se pierde, más bien es la construcción sin salida. Las palabras de Asterión: «otra especie ridícula es que yo, Asterión, soy un prisionero» (Borges 2003, 77) confirman que el protagonista sí es el prisionero de su propio 'hogar'. Visto así se entiende la reconciliación de Asterión con su destino. Según Vid (2004:162) la construcción de laberinto donde vive Asterión es un acto simbólico para Borges, y la imagen de esta prisión es más ilustrativa debido a la sensación de pérdida en el espacio y del movimiento sin rumbo. La imagen del laberinto metaforiza también nuestra experiencia de la vida mortal. 
Cuando se autorretrata, el protagonista acentúa su carácter idiosincrásico. Él representa sus defectos y desventajas como virtudes, escondiéndolas bajo la capa de su espíritu superior e indiferente, como vemos en el siguiente ejemplo:

(3) El hecho es que soy único. No me interesa lo que un hombre pueda transmitir a otros hombres; como el filósofo, pienso que nada es comunicable por el arte de la escritura. Las enojosas y triviales minucias no tienen cabida en mi espíriu, que está capacitado para lo grande; jamás he retenido la diferencia entre una letra y otra. Cierta impaciencia generosa no ha consentido que yo aprendiera a leer. A veces lo deploro, porque las noches y los días son largos. (Borges 2003, 78)

(3a) Činjenica je da sam jedinstven. Ne zanima me šta jedan čovek može da saopšti drugim ljudima; kao onaj filozof i ja smatram da se veštinom pisanja ništa ne može preneti. Za dosadne i proste sitnice nema mesta u mome duhu, koji je predodređen za velike stvari. Ja nikad nisam zapamtio razliku između dva slova. Neko plemenito nestrpljenje nije mi nikad dalo da naučim da čitam. Ponekad zažalim, jer noći i dani su dugi. (Borhes 1999, 60)

Desde el punto de vista traductológico, es interesante comentar el uso del artículo determinado en esta descripción. En primer lugar vale mencionar la traducción del adjetivo único, que según DRAE tiene dos acepciones: a) solo y sin otro de su especie y b) extraordinario, excelente. La solución jedinstven es adecuada, porque, según RMS, el adjetivo serbio tambien conlleva los dos sememas documentados en DRAE. En la traducción de R. Konstantinović el artículo determinado en el sintagma (como) el filósofo informa sobre un referente conocido al narrador y al lector. Se trata de un filósofo en particular y el narrador y receptor del texto saben muy bien quén es este filósofo que sostiene la postura sobre la inutilidad de la escritura.

En comparación con otra solución del traductor Grujičić:

(3b) Da sam besprimeran, u to nema sumnje. Ne zanima me šta čovek čoveku može penetu; poput filozofâ, smatram da se ništa ne dâ saopštiti pisanom veštinom. (Borhes: 2004, 43)

El sintagma nominal el filósofo aquí está transferida al serbio mediante el genitivo plural filozofâ, y entonces se refiere a todos los filósofos, representantes de tal oficio, sin especificación alguna de quién podría tratarse. El uso del adjetivo besprimeran (a diferencia de jedinstven en ZUNS) dificilita la lectura (que incluso puede resultar confusa) e igualmente complica el entendimineto del texto, porque el adjetivo está completamete caído en desuso (en vez de él en el habla se utiliza jedinstven, izuzetan o la construcción nema mu ravnog). El traductor confirma adicionalmente la veracidad de las palabras de Asterión con la forma $u$ to nema sumnje, que entonces funciona como intesificador del enunciado expuesto.

A medida que nos acercamos al final del relato, se nos está haciendo más claro quién en realidad es el protagonista, qué tipo de ser es y para qué le sirven los juegos que juega con sus 'visitantes'. Nos expone más detalles sobre su casa, manifestando implícitamente que está consciente de su destino, que es incapaz de evitarlo, que su casa es su presidio y que no tiene ninguna libertad en absoluto: «La casa es del tamaño del mundo; mejor dicho, es el mundo» (Borges 2003, 79).

(4) Eso no lo entendí hasta que una visión de la noche me reveló que también son catorce [son infinitos] los mares y los templos. Todo está muchas veces, catorce veces, pero dos cosas hay en el mundo que parecen estar una sola vez: arriba, el intrincado sol; abajo, Asterión. (Borges 2003, 80) 
(4a) To nisam shvatio sve dok mi noćna vizija nije otkrila da mora i hramova ima takođe četrnaest (bezbroj). Sve stvari postoje više puta, četrnaest puta, ali dve stvari na svetu izgleda postoje samo jednom: gore, mutno sunce; dole, Asterion. (Borhes 1999, 60)

Como se observa en el ejemplo anterior, los números tienen una función importante y son particularmente desafiantes para traducir. En primer lugar, porque la simbología de los números en Borges es muy diversificada e influye mucho en el entendimiento e interpretación del mensaje. Aunque no es objeto de nuestra investigación interpretar la simbología de números en J. L. Borges, podemos solamente constatar que esta es muy desarrollada y que cada número lleva su propia semántica. Por ejemplo, en La casa de Asterión el número catorce se iguala con la infinitud. Como dice al principio del texto el mismo autor El original dice catorce, pero sobran motivos para inferir que, en boca de Asterión, ese adjetivo numeral vale por 'infinitos' (Borges 2003, 77).

En segundo lugar, por las razones gramaticales de congruencia entre el número y el sustantivo (dentro del sintagma nominal) y por la coherencia textual del sintagma nominal con el resto del texto. En casos como este, Radivoje Konstantinović inclina hacia la opción del genitivo (mora i hramova ima takođe četrnaest (bezbroj). Cuando no es posible ajustar el número con el sintagma en genitivo Konstantinović opta por la solución descriptiva o cambio del verbo, como en la oración Todo está muchas veces, catorce veces (Sve stvari postoje više puta, četrnaest puta).

Mediante el epíteto intrincado colocado al lado del sustantivo sol (también en ej. 4) el autor intensifica el impacto ilustrativo de la imagen que quiere representar. El uso de combinaciones y sintagmas insólitas, como es el caso de el intrincado sol dificilita el trabajo del traductor por un lado (quien debe interpretar el significado del texto original y luego transferirlo y ajustarlo adecuadamente en lengua meta), pero al mismo tiempo lo facilita (porque las combinaciones raras e insólitas no son estrictamente definidas semánticamente y así dejan cierta libertad al traductor en el momento de elegir la solución más adecuada para el contexto dado).

La traducción de este fragmento de Paidea es algo distinta:

(4b) Nisam ih razumeo sve dok mi jedna noćna pričina ne otkri da je četrnaest (ima ih bezbroj) i mora i hramova. Sve je mnogo, četrnaest puta umnoženo, ali dve stvari na ovom svetu kao da postoje samo jednom: gore, vijugavo sunce, i dole, Asterion. (Borhes: 2004: 43)

Vemos que aquí cambia el tipo de adverbio: el adverbio de cantidad (sve je mnogo) por en adverbio de frecuencia (samo jednom). El lexema pričina (en noćna pričina) ni siquiera está documentado en RMS; obviamente se trata del neologismo traductológico (y uno muy efectivo) que se ha generado a partir del verbo pričiniti se (parecer, aparentar, presentarse como). El sintagma intrincado sol - que en la traducción de Konstantinović era mutno sunce (el sol borroso) - aquí es completamente distinto: vijugavo sunce (el sol sinuoso, tortuoso). Ninguna de las opciones coincide en completo con la abstracta y polisémica semántica del adjetivo intrincado; Borges lo utiliza intencionalmente de tal manera que pueda interpretarse de distintos modos. De ahí, ninguna de las opciones traductológicas resulta ser incorrecta.

Terminamos el análisis traductológico en el nivel sintáctico y de la estructura oracional. El traductor Konstantinović muestra la tendencia de cortar las oraciones largas de Borges, de dividirlas en dos, incluso en tres oraciones, reagrupando los elementos sintagmáticos (como en oraciones La gente oraba, huía, se prosternaba; unos se encaramaban al estilóbato del 
templo de las Hachas, otros juntaban piedras; o en la oración Las enojosas y triviales minucias no tienen cabida en mi espíritu, que está capacitado para lo grande;(...)).

(5) Donde cayeron, quedan, y los cadáveres ayudan a distinguir una galería de las otras. (Borges 2003: 80)

(5a) Ostaju tamo gde su pali. Njihovi leševi pomažu mi da razlikujem hodnike.

(Borhes 1999: 61)

Este ejemplo demuestra que con la segmentación de la oración compleja el traductor logra la simplificación y aclaramiento del texto original, contribuyendo al mejor entendimiento de los pensamientos (muchas veces confusos o contradictorios) de la bestia. Estrechamente relacionados con las funciones sintácticas son los signos de puntuación, que naturalmente cambian con la ruptura oracional. Sin embargo, la traducción no produce mayor cambio de tono y de pausas (en comparación con el texto original).

La traducción de Grujičić reproduce el modelo básico de Konstantinović dividiendo la oración compuesta en dos oraciones, pero introduce cambios en nivel léxico.

(5b) Gde padnu tu i ostanu. Docnije mi njihove telesine pomažu da razlikujem hodnike.

(Borhes 2004, 44)

Se introduce el adverbio del tiempo (docnije) con el que se distancian cronológicamente las acciones. El uso del aumentativo telesine en vez de lexema neutro tela (cuerpos) representa las vidas de las víctimas como insignificantes y añade el matiz despreciativo.

\section{OBSERVACIONES FINALES}

Desde que empezó la traducción y publicación de J. L. Borges en Serbia, su obra ha despertado gran interés en el público y en la crítica literaria. La recepción de su obra ha contado con numerosas publicaciones, comentadas y traducidas por hispanistas, romanistas, críticos y escritores de renombre, entre los que ha destacado precisamente Radivoje Konstantinović, como uno de los mejores traductores y expertos de la obra borgeana.

En este trabajo hemos perseguido doble objetivo: en primer lugar hemos elaborado los temas y símbolos frecuentemente empleados por J. L. Borges en su obra prosaica. Nos hemos centrado en su forma de expresarse, en las alusiones y metáforas que desarrolla con su estilo erudito. Dentro del conjunto de los símbolos más recurrentes, hemos optado por investigar el laberinto, como una de las obsesiones borgeanas y como uno de los ejemplos más ilustrativos de su entendimiento del tiempo y espacio. El laberinto en Borges simboliza esta encrucijada témporo-locutiva, construcción que va mucho más allá de lo físico y visual, y llega hasta lo psicológico, onírico, religioso, metafísico. El laberinto, como la prisión para Asterión, para lector, el laberinto lingüístico que rompe la lógica del enunciado.

En la segunda parte, dedicada a la traducción y traductología, hemos partido de las observaciones del mismo Borges sobre estos fenómenos; para él la traducción representa la creación literaria par excellence, una capacidad de conservar y superar la expresión del texto original. También hemos expuesto las corrientes principales en la traductología, especificando nuestro entendimiento de la traducción y estableciendo el marco teórico para el análisis traductológico.

Al final hemos comentado algunas soluciones traductológicas del relato La casa de Asterión que creemos ser interesantes para análisis contrastivo español-serbio. El análisis de 
ciertos elementos gramaticales y estilísticos indican que el profesor Konstantinović como traductor de la prosa borgeana inclina hacia la conservación del estilo culto y erudito del autor (por ejemplo cuando preserva lexemas raros o arcaicos), pero que al mismo tiempo simplifica sus enunciados que serían demasiado complicados o difíciles de incorporar al sistema lingüístico serbio (cortando las oraciones complejas, introduciendo nuevos signos de puntuación, parafraseando los sintagmas etc.).

\section{Hay quienes no pueden imaginar un mundo sin pájaros, hay quienes no pueden imaginar un mundo sin agua; en lo que a mí se refiere, soy incapaz de imaginar un mundo sin libros.}

(Jorge Luis Borges)

\section{Fuentes}

\section{REFERENCIAS BIBLIOGRÁFICAS}

Borges, Jorge Luis. "La casa de Asterión”, en: El Aleph. 77-81. Madrid, Alianza, 2003.

Borhes, Horhe Luis. "Asterionov dom”, en: Iščekivanje i druge priče. Beograd, ZUNS (traducción de Radivoje Konstantinović), 1999, pp. 59-61.

Borhes, Horhe Luis. "Asterionov dom.” Alef. Beograd, Paidea (traducción de Aleksandar Grujičić), 2004, pp. $42-45$.

\section{Monografías, diccionarios}

DRAE. Diccionario de la Lengua Española. Madrid, Real Academia Española, 2014.

Iñesta Mena, Eva, Antonio Pamies Bertrán. Fraseología y metáfora: aspectos tipológicos y cognitivos. Granada, Método, 2002.

Ivir, Vladimir. Teorija i tehnika prevođenja. Sremski Karlovci, Centar "Karlovačka gimnazija”, 1978.

Hurtado Albir, Amparo. Traducción y traductología. Introducción a la traductología. Madrid, Cátedra, 2007.

Konstantinović, Radivoje, Filip Matić i Marko Nedić (ed.). Horhe Luis Borhes. Radovi sa književno-naučnog skupa posvećenog H.L.Borhesu (24-25.09.1996). Beograd, Zavod za udžbenike i nastavna sredstva, SKZ, JUL, 1997.

Newmark, Peter. Manual de traducción. Madrid, Cátedra, 2010.

Nord, Christiane. Texto base-texto meta. Un modelo funcional de análisis pretraslativo. Castelló de la Plana, Publicacions de la Universitat Jaume I, 2012.

RMS. Rečnik srpskoga jezika. Novi Sad, Matica srpska, 2007.

RMS/MH. Rečnik srpskohrvatskoga književnog jezika: I-VI. Novi Sad, Matica srpska, Zagreb, Matica hrvatska, 1967-1976.

Živković, Dragiša. Rečnik književnih termina, Beograd, Nolit, 1986.

\section{Artículos}

Delić, Jovan. "Fragmenti o H. L. Borhesu u srpskoj književnosti”, en: Horhe Luis Borhes, R. Konstantinović, F. Matić, M. Nedić. Beograd, ZUNS, SKZ, JUL, 1997, pp. 112-129.

Kiš, Danilo. "Fragmenti o Borhesu”, en: Horhe Luis Borhes, R. Konstantinović, F. Matić, M. Nedić. Beograd, ZUNS , SKZ, JUL, 1997, pp. 338-341.

Lukić, Ljiljana. "Stvarnost ili mit”, en: Horhe Luis Borhes, R. Konstantinović, F. Matić, M. Nedić. Beograd, ZUNS, SKZ, JUL, 1997, pp. 205-215.

Nord, Christiane. "La unidad de traducción en el enfoque funcionalista." Quaderns: Revista de traducció, no.1, 1998, 65-77.

Konstantinović, Radivoje. "Predgovor. Klasik XX veka”, en: Iščekivanje i druge priče. Horhe Luis Borhes. Beograd, Zavod za udžbenike i nastavna sredstva, 1999, pp. 7-30.

Konstantinović, Radivoje. "Argentinac kosmopolita”, en: Horhe Luis Borhes, R. Konstantinović, F.Matić, M.Nedić. 23-29. Beograd, ZUNS , SKZ, JUL1997. 
Konstantinović, Radivoje. "Prevoditi Borhesa", en: Horhe Luis Borhes, R. Konstantinović, F.Matić, M.Nedić. 225226. Beograd, ZUNS , SKZ, JUL1997.

Matić, Filip, Marko Nedić. "Uvodne napomene. Notas de introduccion” en: Horhe Luis Borhes, R. Konstantinović, F.Matić, M.Nedić. Beograd, ZUNS, SKZ, JUL, 1997, pp. 5-20.

Prelević, Branislav. "Bohesovski infinitum” en: Horhe Luis Borhes, R. Konstantinović, F. Matić, M. Nedić. Beograd, ZUNS, SKZ, JUL, 1997, pp.103-106.

Pejčić, Bogumira. "Borhesova ruža apartida" en: Horhe Luis Borhes, R. Konstantinović, F. Matić, M. Nedić. Beograd, ZUNS, SKZ, JUL, 1997, pp. 167-171.

Puslojić, Adam. "Bohesovski infinitum" en: Horhe Luis Borhes, R. Konstantinović, F .Matić, M. Nedić. Beograd, ZUNS, SKZ, JUL1997, pp. 77-83.

Šukalo, Mladen. "Kišovi palimpsesti prema Borhesu" en: Horhe Luis Borhes, R. Konstantinović, F. Matić, M. Nedić. 1997. Beograd, ZUNS, SKZ, JUL1997, pp. 131-141.

\section{Publicaciones en línea}

Almeida, Iván. "Borges o los laberintos de la inmanencia", en: Rafael Olea Franco (ed.), Borges: desesperaciones aparentes y consuelos secretos, Mexico, Colegio de Mexico, 1999 (accesble en: http://www.borges.pitt.edu/sites/ default/files/Almeida\%20Borges\%20o\%20los\%20laberintos.pdf, accedido: 18.10.2018.).

Borges, Jorge Luis. "Las dos maneras de traducir.” Emecé, Buenos Aires. [1926] 1997, pp. 256-259. (accesble en: www.cervantesvirtual.com accedido 11.04.2017.)

Carmen Balart, Carmona, Irma Césped Benítez. "Temas recurrentes en la literatura borgeana" Cuaderno de la Facultad, 2010 (accesble en: http://entretextosborges.blogspot.rs/2010/03/temas-recurrentes-en-la-literatura.html accedido 17.12.2018.)

García Ramos, Juan Manuel. "Borges y la tradición metafórica." Revista de Filología de la Universidad de La Laguna, XX, 2002, pp. 121-134 (accesble en: https://dialnet.unirioja.es accedido 03.10.2017.)

Kristal, Efraín. "Borges y la traducción." Lexis, XXIII, 1999, pp. 3-23. (accesble en: revistas.pucp.edu.pe/ index.php/lexis/article/download/ accedido 23.01.2019.)

Palomo García, Carmen. "Hermenéutica en Borges." Revista Semestral de Iniciación a la Investigación en Filología, II, 2010, 29-52

(accesble en: https://w3.ual.es/revistas/PhilUr/pdf/PhilUr2.2010.Palomo.pdf accedido 20.01.2019.)

Quintana Tejera, Luis. "La conciencia atormentada de un monstruo abandonado. 'La casa de Asterión' de J. L. Borges.” Culturales, VII, 2011 (accesble en: https://scielo.org.mx accedido 14.07.2017.)

Weed, Ethan. “A Labyrinth of Symbols: Exploring 'The Garden of Forking Paths”, Variaciones Borges, 18, 2004, pp. 161-189 (accesble en: http://www.borges.pitt.edu/sites/default/files/1808.pdf, accedido: 02.3.2019.).

\section{SIMBOLIČKI JEZIK H. L. BORHESA U INTERPRETACIJI I PREVODIMA RADIVOJA KONSTANTINOVIĆA}

U radu smo postavili dvostruki cilj: prvo, istražujemo teme, motive i metafore koje u svojim proznim delima obrađuje Horhe Luis Borhes sa posebnim osvrtom na recepciju njegovog dela u srpskoj čitalačkoj sredini. Među najčešćim motivima posebno mesto zauzima lavirint, sa svojom simbolikom prostorne, vremenske, psihološke, egzistencijalne i oniričke konstrukcije. Tumačenje baziramo, između ostalog, na zapažanjima i kritikama profesora Radivoja Konstantinovića, vrsnog prevodioca i jednog od najboljih poznavalaca Borhesovog dela kod nas. Za drugi cilj smo postavili traduktološku analizu u kojoj istražujemo prevodilačka rešenja i postupke koje u svom prevodu na srpski primenjuje profesor Konstantinović. $U$ analizi polazimo od sistemske i hijerarhijski ustrojene prirode jezika, i u skladu s tim komentarišemo ona gramatička $i$ stilistička prevodilačka rešenja koja smatramo interesantnim za govornike srpskog jezika. Korpus je baziran na priči La casa de Asterión $i$ na njenom srpskom prevodu Asterionov dom (ZUNS). Istraživanje poput ovog iziskuje metodološki okvir koji obuhvata metaforičku / simboličku interpretaciju motiva (kada predstavljamo $i$ analiziramo dominantne ideje $i$ simbole Borhesove proze), lingvističku i prevodilačku analizu proznog teksta, kao i kontrastivnu analizu (koja se bazira na paralelnim prevodnim korpusima sa ciljem upoređivanja različitih traduktoloških rešenja za prevod istog teksta).

Ključne reči: prevođenje, simbol, metafora, lavirint, H. L. Borhes, R. Konstantinović 